\title{
Constraining sulphide weathering in the Mackenzie Basin using molybdenum isotopes
}

\author{
QUENTIN CHARBONNIER ${ }^{1}$, COREY ARCHER ${ }^{2}$, JULIEN \\ BOUCHEZ ${ }^{3}$, JÉRÔME GAILLARDET ${ }^{4}$, ROBERT G \\ HILTON $^{5}$ AND DEREK VANCE ${ }^{2}$ \\ ${ }^{1}$ Institute of Geochemistry and Petrology, Department of Earth \\ Sciences, ETH Zürich \\ ${ }^{2}$ ETH Zürich \\ ${ }^{3}$ Institut de Physique du Globe de Paris \\ ${ }^{4}$ Université de Paris-Institut de Physique du Globe de Paris- \\ CNRS, UMR 7154 \\ ${ }^{5}$ Durham University \\ Presenting Author: quentin.charbonnier@erdw.ethz.ch
}

The long-term climate of the Earth is regulated through two different chemical weathering pathways. On the one hand, the dissolution of silicate rocks by carbonic acid removes atmospheric $\mathrm{CO}_{2}$ and stores it in carbonate rock. On the other, the dissolution of carbonate rocks by sulfuric acid, deriving from the oxidation of sulphide released from minerals like pyrite, releases $\mathrm{CO}_{2}$ into the atmosphere [1]. The relative global magnitudes of these processes remain uncertain because of the difficulty in quantifying fluxes of carbonate dissolution by sulfuric acid, especially in large river catchments [1,2]. This is due to the fact that carbonate dissolution $\left(\mathrm{CaCO}_{3}\right)$ by sulfuric acid $\left(\mathrm{H}_{2} \mathrm{SO}_{4}\right)$ produces a solute chemical composition close to that yielded by gypsum dissolution $\left(\mathrm{CaSO}_{4}\right)$.

To shed light on the different weathering pathways, we explore the potential of Mo and its isotopes in the riverine dissolved load of the Mackenzie Basin to trace sulphide oxidation and subsequent rock dissolution [3]. In the Mackenzie Basin, dissolved Mo isotope composition is closely related to the production of sulfuric acid, suggesting in turn a strong influence of sulphide oxidation on the Mo weathering signature. The formation of secondary clay or hydroxide phases - though important at the basin-scale in some catchments [4] - seems to have a limited influence on dissolved Mo isotopes in the Mackenzie. Such a near-conservative behavior of Mo and its isotopes permits the use of a set of mixing equations to robustly quantify each weathering pathway. We will use these data to address the overall controlling factors, such as runoff or erosion rates, on both sink and source of $\mathrm{CO}_{2}$ via chemical weathering in the Mackenzie Basin.

[1]Calmels, D., et al. (2007). Geology, 35(11), 1003-1006.

[2]Burke, A., et al. (2018). Earth and Planetary Science Letters, 496, 168-177.

[3]Neubert, N., et al. (2011). Earth and Planetary Science Letters, 304(1-2), 180-190.

[4] Revels, B. N., et al. (2021). Earth and Planetary Science Letters, 559, 116773. 